\title{
Controle Químico do Crestamento Gomoso do Caule em Melancia*
}

\author{
Gil R. Santos ${ }^{1,2}$, Adalberto C. Café-Filho ${ }^{2 * *} \&$ Luciano M. F. Saboya ${ }^{1}$ \\ ${ }^{1}$ Campus de Gurupi, Universidade Federal de Tocantins/Agronomia, Cx. Postal 66, CEP 77400-000, Gurupi, TO, \\ e-mail: gilrsan@uol.com.br; ${ }^{2}$ Departamento de Fitopatologia, Universidade de Brasília, CEP 70910-900 Brasília, DF
}

(Aceito para publicação em 13/01/2005)

Autor para correspondência: Gil R. Santos

SANTOS, G.R., CAFÉ-FILHO, A.C. \& SABOYA, L.M.F. Controle químico do crestamento gomoso do caule na cultura da melancia. Fitopatologia Brasileira 30:155-163. 2005.

\section{RESUMO}

O objetivo deste trabalho foi estudar o efeito de fungicidas e da adubação de cobertura na severidade do crestamento gomoso do caule, em melancia (Citrullus lanatus). Foram conduzidos dois ensaios fatoriais em campo, no Projeto Formoso, Tocantins, em delineamento de blocos ao acaso com quatro repetições, e parcelas experimentais de $30 \times 10 \mathrm{~m}$. Para o ensaio I, os tratamentos (fator a) constaram dos seguintes ingredientes ativos de fungicidas/100 1 de água ou ha: (1) mancozeb (MANC)-160,2 ml, (2) tiofanato metílico (TM)-49 g, (3) carbendazim-500 ml, (4) tebuconazole-20 g, (5) difenoconazole (DIFE)-75 ml, (6) tiofanato metílico-40 g + clorotalonil-100 g, (7) oxicloreto de cobre-168 g, (8) trifloxistrobina-87,5 g + propiconazole-87,5 g, (9) mancozeb- $80 \mathrm{ml}$ + difenoconazole-37,2 $\mathrm{ml}$ e (10) testemunha. No fator b, estudou-se a adubação de cobertura (N-K) nos níveis de 30-20 e 90-60 kg/ha. A severidade da doença nas folhas foi avaliada com uma escala de notas de 0 a 9. Para o ensaio II, repetiram-se os tratamentos do fator a, enquanto o fator b (níveis de adubação), foram: 60-40 e 120-80 kg/ha de N-K. Nos dois ensaios as menores Áreas Abaixo da Curva de Progresso de Doença (AACPD) foram obtidas com MANC + DIFE, TM + clorothalonil, MANC, trifloxistrobina + propiconazole e oxicloreto de cobre. A adubação de cobertura não influenciou a severidade da doença. As produtividades mais altas foram obtidas com TM + clorotalonil, MANC + DIFE e MANC que diferiram estatisticamente do DIFE, testemunha e trifloxistrobina + propiconazole.

Palavras-chave adicionais: Citrullus lanatus, Didymella bryoniae, fungicidas.

\begin{abstract}
Chemical control of watermelon gummy stem blight

This work reports the results of the effects of chemical control and nitrogen-potassium fertilization on gummy stem blight, one of the most important watermelon (Citrullus lanatus) diseases. Two factorial field assays were conducted in Projeto Formoso, Tocantins, in a randomized block design with four replicates. Experimental plots measured $30 \times 10 \mathrm{~m}$. Treatments for assay I were (factor a - active ingredients/100 1 water or ha): (1) mancozeb (MANC)-160.2 ml, (2) methyl thiophanate (TM)-49 g, (3) carbendazin-500 ml, (4) tebuconazole- $20 \mathrm{~g}$, (5) difenoconazole (DIFE)-75 ml, (6) methyl thiophanate-40 g + chlorothalonil -100 g, (7) copper oxychlorate-168 g, (8) trifloxistrobina-87.5 g + propiconazole-87.5 g, (9) mancozeb-80 ml + difenoconazole- $37.2 \mathrm{ml}$, and (10) control. Treatments for factor b were two levels of N-K fertilization: (1) 30-20, and (2) $90-60 \mathrm{~kg} / \mathrm{ha}$. Disease severity on leaves was evaluated on a 0 to 9 scale. For the assay II, treatments for factor a were repeated, while treatments for factor $\mathrm{b}$ were $\mathrm{N}-\mathrm{K}$ fertilization levels $(\mathrm{kg} / \mathrm{ha})$ 60-40 and 120-80. On both assays, lowest Areas Under Disease Progress Curves (AUDPD), were obtained with MANC + DIFE, TM + chlorothalonil, MANC, trifloxistrobina + propiconazole and copper oxychlorate. Fertilization did not affect disease severity. Larger yields were obtained with TM + chlorothalonil, MANC + DIFE and MANC.
\end{abstract}

Additional keywords: Citrullus lanatus, Didymella bryoniae, fungicides.

\section{INTRODUÇÃO}

A cultura da melancia [Citrullus lanatus (Thunb) Mansf.] constitui-se em atividade agrícola importante para o Brasil, proporcionando retorno econômico para o produtor, e devido exigir mão-de-obra intensiva, é empregadora de mão de obra rural. Segundo a FAO (2002), no Brasil, a melancia ocupa uma área de 82.000 ha e um volume de produção de $620.000 \mathrm{t}$, representando assim uma produtividade média de 7,56 t/ha. Entre os estados maiores produtores estão São Paulo,

\footnotetext{
*Parte da tese de Doutorado do primeiro autor apresentada à Universidade de Brasília, UnB. (2005)

**Bolsista de Pesquisa do CNPq
}

Rio Grande do Sul, Bahia, Goiás e Tocantins (Alencar, 2001). $\mathrm{O}$ Estado do Tocantins tem uma área plantada em torno de 3.000 ha (César \& Santos, 2001) e produtividade média de 30 t/ha (Santos et al., 2001). Com solos de boa fertilidade, clima favorável e água em abundância a planta começa a produzir com cerca de 75 dias após o plantio (Santos et al. 2001). Na região, existem grandes reservatórios de água acumulada durante os meses de outubro a abril, e a planta encontra as condições ideais para o seu desenvolvimento, tanto em termos de fertilidade do solo como também no clima quente e boa luminosidade durante toda a safra da cultura que ocorre nos meses de maio a setembro.

Dos fatores limitantes à produção, as doenças 
provocam danos e redução na produtividade e na qualidade dos frutos, haja vista que uma pequena mancha na casca leva ao descarte do fruto para o mercado, além de elevar o custo de produção com o uso excessivo de defensivos (César \& Santos, 2001). Dentre as doenças, o crestamento gomoso do caule [Didymella bryoniae (Auersw) Rehm] é uma das principais (Santos et al. 2003). Os sintomas incluem cancro no caule, queima das folhas e também pode provocar apodrecimento de frutos (Schenck, 1968). A doença vem despertando preocupação também nos perímetros irrigados do nordeste (Dias et al. 1996), e em outros países como nos Estados Unidos (Schenck, 1960; Sitterly \& Keinath, 1996; Keinath \& Duthie, 1998; Everts, 1999) e no Caribe tropical (Bala \& Hosein, 1986). O agente causal é o fungo D. bryoniae [=Mycosphaerella citrullina (C.O. Sm.) Gross.], anamorfo Ascochyta cucumis Fautrey \& Roum [=Phoma cucurbitacearum (Fr.) Sacc.)], e tem como hospedeiro diversas espécies dos gêneros Citrullus, Cucumis, Cucurbita, e outros (Keinath, 1995). Figueiredo \& Cardoso (1964) registraram a doença no Brasil. Existem poucas cultivares de espécies de cucurbitáceas com boa aceitação comercial resistentes a este patógeno (McGrath et al. 1993; Sumner \& Hall, 1993; Wehner \& Amand, 1993; Dias et al. 1996) e o controle da doença é feito principalmente com fungicidas (Keinath, 1995). A baixa eficiência do controle químico tem sido atribuída à rápida infecção das folhas por D. bryoniae (Van Steekelenburg, 1985; Arny \& Rowe, 1991), ou à resistência a determinados princípios ativos (Malathrakis \& Vakalounakis, 1983).

No Brasil, há escassez de trabalhos de controle químico desta doença, bem como dos efeitos da adubação no progresso da doença em campo. Este trabalho teve por objetivo estudar o controle químico do crestamento gomoso do caule na cultura da melancia sob diferentes níveis de adubação de cobertura.

\section{MATERIAL E MÉTODOS}

Foram conduzidos dois ensaios em condições de campo com histórico de plantio comercial de melancia nos últimos dez anos, no Projeto Rio Formoso, em Formoso do Araguaia, Tocantins, no período de maio a agosto de 2003. O delineamento experimental foi de blocos casualizados, em esquema fatorial de $10 \times 2$, sendo o fator a representado por dez fungicidas e o fator $b$ por dois níveis de adubação de cobertura, com quatro repetições.

\section{Ensaio I}

O preparo do solo constou de aração e gradagem seguido de sulcagem. A adubação de base foi feita com 650 $\mathrm{kg} / \mathrm{ha}$ da fórmula $05-25-15$ de N-P-K. Cada parcela foi constituída de 30 plantas semeadas no espaçamento de 2,70 x $0,90 \mathrm{~m}$ com a cv. Crimson Sweet, suscetível ao crestamento gomoso. Atualmente esta cultivar é a mais plantada em todo o território nacional devido ser produtiva e de boa aceitação no mercado. A irrigação foi feita por levantamento do lençol freático nas áreas sistematizadas, conforme a técnica utilizada na região. Foram feitas duas capinas manuais, aos 15 e 30 dias pós-semeadura. Não foi feita inoculação nas plantas devido ao fato de o ensaio ter sido instalado em área infestada e com histórico da doença. Os tratamentos (fator a) constaram dos seguintes ingredientes ativos de fungicidas aplicados nas suas respectivas doses do produto comercial: 1-mancozeb160,2 $\mathrm{ml}$ (Persist-360 ml P.C./100 1 de água), 2-Tiofanato metílico-49 g (Cercobin-70 g P.C./100 1), 3-carbendazim-500 $\mathrm{ml}$ (Derosal-1 1 P.C./ha), 4-tebuconazole-20 g (Folicur-100 g P.C./100 1), 5-difenoconazole-75 $\mathrm{ml}$ (Score-300 ml P.C./ha 1), 6-tiofanato metílico- $40 \mathrm{~g}$ + clorotalonil-100 g (Cerconil200 g P.C./100 1), 7-oxicloreto de cobre-168 g (Cobox-200g P.C./100 l), 8-trifloxistrobina-87,5 g + propiconazole-87,5 g (Stratego-700 $\mathrm{ml}$ P.C./ha), 9-mancozeb-80 $\mathrm{ml}+$ difenoconazole-37,2 ml (Persist-180 ml P.C./100 l + Score$150 \mathrm{ml} \mathrm{P.C./ha,} \mathrm{respect.)} \mathrm{e} \mathrm{10-testemunha} \mathrm{(sem} \mathrm{fungicida).}$ Dentre os produtos comerciais citados, são atualmente registrados para a cultura da melancia: Cercobin, Folicur, Cerconil e Cobox (Andrei, 1999, 2003). Os fungicidas foram aplicados com pulverizador costal a um volume de 300 1/ha em intervalos variando entre sete a dez dias. As pulverizações iniciaram-se a partir de 17 dias após o plantio (DAP), no período vegetativo da cultura, se estendendo pelos estádios de floração e frutificação, sendo que a última pulverização foi realizada aos 73 DAP, na pré-colheita, perfazendo um total de oito aplicações durante o ciclo da cultura.

No fator $b$, estudaram-se dois níveis de adubação de cobertura. Cada parcela foi demarcada ao meio, onde de um lado da parcela, testou-se em 15 plantas, os níveis de 30-20 $\mathrm{kg}$ e do outro $90-60 \mathrm{~kg} / \mathrm{ha}$ de nitrogênio e potássio aplicados através da fórmula 30-00-20 de N-P-K. A cobertura foi realizada aos 25 DAP.

Nas folhas, a doença foi avaliada semanalmente por meio da utilização de uma escala de notas de 0 a 9 , onde: 0 planta sadia; 1-menos de 1\% da área foliar afetada; 3 - entre 1 a $5 \%$ da área foliar afetada; 5-entre 6 a $25 \%$ da área foliar doente; 7 -entre $26-50 \%$ da folha doente; 9 -mais que $50 \%$ da área foliar afetada.

A colheita foi feita 80 dias após a semeadura, quando se realizou a contagem e pesagem dos frutos comerciais (peso $\geq 3,0 \mathrm{~kg}$ ). As seguintes variáveis foram registradas: Percentagem de área foliar doente aos 47, 52, 58 e 68 dias após o plantio, Incidência de cancro no caule aos 47, 52, $58 \mathrm{e}$ 68 dias após o plantio, Número total de frutos infectados (FI), Número total de frutos comerciais (NTF) e Produtividade ( $t$ / ha). Como variável secundária, foi calculada a Área Abaixo da Curva de Progresso da Doença (AACPD), da porcentagem de área foliar doente, conforme Shaner \& Finney, (1977). Antes das análises, as notas atribuídas à doença nas folhas foram convertidas para porcentagens de área foliar doente pelo ponto médio de cada nota e os dados transformados pelo arco seno da raiz quadrada para normalização da distribuição estatística (Gomez \& Gomez, 1983).

Foram realizadas análises de variância para cada variável dentro dos tratamentos e nos dois níveis de adubação de cobertura, analisando-se suas interações. As médias foram 
Controle químico do crestamento gomoso do caule na cultura...

comparadas pelo teste de Tukey, ao nível de $5 \%$ de probabilidade (Gomez \& Gomez, 1983). Obteveram-se as equações de regressão doença vs. tempo para cada tratamento fungicida. Também foi estudada a correlação entre AACPD e a produtividade da melancia nos níveis de adubação de cobertura com nitrogênio e potássio (N-K) e fungicidas.

\section{Ensaio II}

Utilizou-se a mesma metodologia descrita no ensaio anterior, diferindo-se apenas no local do experimento (módulo I1 1 do Projeto Rio Formoso, Tocantins) e nos níveis do fator b (adubação de cobertura) onde testou-se os níveis de 60-40 e $120-80 \mathrm{~kg} / \mathrm{ha}$ de $\mathrm{N}-\mathrm{K}$, da fórmula 30-00-20.

As temperaturas médias, máxima e mínima, e a umidade relativa do ar foram monitoradas diariamente em estação meteorológica localizada no Projeto Rio Formoso, Tocantins, distanciada a $4 \mathrm{~km}$ do local do ensaio Ie a $3 \mathrm{Km}$ do ensaio II.

\section{RESULTADOS}

A doença ocorreu naturalmente no experimento. $\mathrm{O}$ sintoma de cancro no caule, no ensaio I, apareceu a partir dos 20 DAP e não mais aumentou a partir dos 33 DAP; no ensaio II , iniciou-se aos 20 DAP e houve progresso até os 40 DAP. O sintoma de crestamento nas folhas iniciou-se a partir dos 47 DAP em alguns tratamentos, porém houve aumento brusco da doença principalmente aos 58 e 68 DAP. Maiores níveis de crestamento foliar ocorreram no módulo I1 1 quando comparado com o módulo F5.

Menores AACPDs foram encontradas nos tratamentos com mancozeb + difenoconazole, tiofanato metílico + clorotalonil, mancozeb, trifloxistrobina + propiconazole e oxicloreto de cobre que diferiram estatisticamente dos demais tratamentos (Tabela 1). Resultado semelhante ocorreu no ensaio II (Tabela 5).

Não houve diferença estatística entre os tratamentos no controle do cancro no caule (Tabelas 1 e 5). No ensaio I, houve incidência variando de 0,2 a $1,0 \%$ e de 0,4 até $1,2 \%$ no ensaio II. A adubação de cobertura não influenciou a incidência de cancro no caule entre os fungicidas testados (Tabelas 2, 3 e 7).

Em ambos os ensaios as mais altas produtividades foram obtidas nos tratamentos com tiofanato metílico + clorotalonil, mancozeb + difenoconazole e mancozeb que diferiram estatisticamente de difenoconazole, testemunha e trifloxistrobina + propiconazole (Tabelas 1 e 5). O tratamento com trifloxistrobina + propiconazole foi eficiente no controle da doença nas folhas, porém não resultou em boa produtividade e foi associado a sintomas de fitotoxidez nas plantas, principalmente quando aplicado na fase jovem da cultura. Todos os outros tratamentos que reduziram a doença nas folhas também proporcionaram boa produtividade da cultura. No ensaio I, apenas o oxicloreto de cobre diferiu estatisticamente da testemunha no total de frutos infetados (FI). Menor Número total de frutos (NTF) foi encontrado nos tratamentos com trifloxistrobina + propiconazole e difenoconazole e maior NTF com o tratamento com mancozeb (Tabela 1). No ensaio II (Tabela 5), não houve diferença estatística entre os tratamentos com relação NTF ou FI.

No ensaio I, menor produtividade foi obtida com 30$20 \mathrm{~kg} / \mathrm{ha}$ de N-K, quando comparado com a cobertura com 90-60 kg/ha (Tabela 3). A adubação com 90-60 kg/ha de N-K aumentou o NTF, mas não influenciou no FI, Incidência de cancro no caule, ou na Percentagem de área foliar doente. No ensaio II, menor produtividade da melancia foi obtida no tratamento com $60-40 \mathrm{~kg} / \mathrm{ha}$ de N-K, quando comparado com a cobertura com 120-80 kg/ha. A adubação com 120-80 kg/ ha de N-K aumentou o NTF, porém não influenciou significativamente nos FI, ou na Incidência de cancro no caule ou na Percentagem de área foliar doente (Tabela 7). Houve interação significativa entre fungicidas e adubação no ensaio II para Percentagem de área foliar doente apenas para o tratamento com tiofanato metílico + clorotalonil (Tabela 6).

$\mathrm{O}$ controle da doença não diferiu significativamente entre e dentro dos tratamentos até o período de 52 DAP, no ensaio I (Tabela 4) e aos e 47 DAP no ensaio II (Tabela 8). Nos dois ensaios, os menores níveis de área foliar doente foram obtidos nos tratamentos com mancozeb + difenoconazol, tiofanato metílico + clorotalonil, trifloxistrobina + propiconazol, mancozeb e oxicloreto de cobre. Nestes tratamentos a doença não aumentou muito no período de 52, 58 até os $68 \mathrm{DAP}$, enquanto que os demais tratamentos não diferiram da testemunha e houve um aumento significativo da doença a partir dos 52 até os 68 DAP (Figura 1 A e B). Houve correlação negativa entre AACPD e a produtividade da melancia, dentro dos quatro níveis de adubação testados, indicando que independente da adubação que foi utilizada neste estudo, quanto maior o nível de doença observada nas folhas menor a produtividade da cultura (Figura $2 \mathrm{~A}, \mathrm{~B}, \mathrm{C}$ e D).

A umidade relativa do ar durante a condução do experimento manteve-se em torno de $60-70 \%$, porém houve uma diferença térmica em torno de $20^{\circ} \mathrm{C}$ entre as médias de temperatura máxima e mínima (Figura 3). Esse fato deverá ter influenciado na ocorrência do molhamento foliar favorecendo a doença nos dois ensaios.

\section{DISCUSSÂO}

Em geral, as maiores intensidades de doença ocorreram na testemunha, onde não se fez aplicação de fungicidas. Os fungicidas tebuconazole, tiofanato metílico, difenoconazole e carbendazim não diferiram estatisticamente da testemunha. Por outro lado, as misturas de tiofanato metílico + clorotalonil, mancozeb + difenoconazole, trifloxistrobina + propiconazole e os produtos isolados mancozeb e oxicloreto de cobre reduziram significativamente a doença nos dois ensaios. Keinath (1995), testando vários fungicidas em diferentes épocas e intervalos de aplicação no controle do crestamento gomoso do caule verificou que a combinação de um fungicida protetor (clorotalonil) com um sistêmico (benomil) reduziu o nível e a taxa de progresso da doença no campo. Efeito benéfico da mistura de princípios 
TABELA 1 - Valores médios do Número total de frutos (NTF), total de frutos infetados, incidência de cancro no caule, percentagem de área foliar infetada, Área Abaixo da Curva de Progresso de Doença (AACPD) e produtividade da melancia (Citrullus lanatus) submetida ao tratamento com fungicidas, no Projeto Formoso, Ensaio I

\begin{tabular}{|c|c|c|c|c|c|}
\hline $\begin{array}{l}\text { Tratamento } \\
\text { (Fungicidas, P.C.) }\end{array}$ & $\begin{array}{l}\text { AACPD da \% } \\
\text { área foliar } \\
\text { infetada }\end{array}$ & $\begin{array}{c}\text { Incidência de } \\
\text { cancro no } \\
\text { caule }(\%)^{*}\end{array}$ & $\begin{array}{l}\text { Total de frutos } \\
\text { NTF/15 plantas** }\end{array}$ & $\begin{array}{l}\text { Frutos infetados } \\
\text { (FI)/15 plantas* }\end{array}$ & $\begin{array}{l}\text { Produtividade } \\
\quad \text { (ton/ha) }\end{array}$ \\
\hline Tiof. metil. + clorotalonil & $8,9 \quad b^{* * *}$ & 0,0 & $20,5 a b * * *$ & $2,2 \mathrm{ab}^{* * *}$ & $54,7 \mathrm{a}^{* * *}$ \\
\hline Mancozeb + difenoconazole & $8,8 \mathrm{~b}$ & 1,0 & $19,3 \mathrm{ab}$ & $3,0 \mathrm{ab}$ & $53,4 \mathrm{a}$ \\
\hline Mancozeb & $8,9 \mathrm{~b}$ & 0,2 & $21,8 \mathrm{a}$ & $3,6 \mathrm{ab}$ & $49,9 \mathrm{ab}$ \\
\hline Trifloxistrobina + propiconazole & $10,1 \mathrm{~b}$ & 0,2 & $16,7 \mathrm{~b}$ & $1,8 \mathrm{ab}$ & 44,4 bc \\
\hline Oxicloreto de cobre & $13,3 \mathrm{~b}$ & 0,8 & $18,2 \mathrm{ab}$ & $1,5 \mathrm{~b}$ & $48,2 \mathrm{abc}$ \\
\hline Tebuconazole & $218,0 \mathrm{a}$ & 0,4 & $17,5 \mathrm{~b}$ & $2,7 \mathrm{ab}$ & $48,3 \mathrm{abc}$ \\
\hline Tiofanato metílico & $301,2 \mathrm{a}$ & 0,0 & $19,2 \mathrm{ab}$ & $4,5 \mathrm{a}$ & $46,7 \mathrm{abc}$ \\
\hline Difenoconazole & $263,6 \mathrm{a}$ & 0,6 & $17,0 \mathrm{~b}$ & $2,6 \mathrm{ab}$ & $41,3 \quad \mathrm{c}$ \\
\hline Carbendazim & $286,5 \mathrm{a}$ & 0,0 & $19,1 \mathrm{ab}$ & $4,6 \mathrm{a}$ & $46,7 \mathrm{abc}$ \\
\hline Testemunha (sem fungicida) & $269,9 \mathrm{a}$ & 0,6 & $18,5 \mathrm{ab}$ & $4,7 \mathrm{a}$ & $43,0 \mathrm{bc}$ \\
\hline Coeficiente de Variação & 10,9 & 25,7 & 6,3 & 21,8 & 5,2 \\
\hline
\end{tabular}

*Dados originais transformados arcoseno $\sqrt{ } \mathrm{x}+1 / 100$;

**Dados originais transformados em $\sqrt{ } \mathrm{x}+1$;

***Médias seguidas da mesma letra nas colunas não diferem entre si, de acordo com o teste de Tukey, $5 \%$.

TABELA 2 - Análise de variância da incidência de cancro no caule da melancia (Citrullus lanatus) tratada com fungicidas e dois níveis de adubação de cobertura com N-K no Projeto Formoso, Ensaio I

\begin{tabular}{lcc}
\hline \hline Fonte de variação & GL & Quadrado médio \\
\hline Fungicida (a) & 9 & 1,06 N.S. \\
Adubação (b) & 1 & 1,59 N.S \\
a x b & 9 & 1,63 N.S. \\
blocos & 3 & 0,31 N.S. \\
resíduo & 57 & 0,78 \\
\hline
\end{tabular}

fungicidas na incidência de cancro no caule, Número total de frutos e Total de frutos infetados. A dose da adubação de cobertura teve efeito no NTF. Com relação ao sintoma de cancro no caule não houve influência dos fungicidas, pois de acordo com observações em áreas de produtores, a entrada do patógeno no caule da planta é favorecida pelos ferimentos provocados durante as operações de capinas. Para a melancia é importante que esta prática seja feita de forma manual, pois não existem herbicidas registrados para a cultura, além desta ser altamente sensível a estes produtos. Porém, o produtor

TABELA 3 - Percentagem de área foliar infetada, incidência de cancro no caule, número total de frutos (NTF), total de frutos infetados e produtividade da melancia (Citrullus lanatus) submetida a dois níveis de adubação de cobertura com nitrogênio $(\mathrm{N})$ e potássio (K), no Projeto Formoso, Ensaio I

\begin{tabular}{lccccc}
\hline $\begin{array}{c}\text { Adubação de cobertura } \\
\text { (Kg.N-K/ha) F.30-00-20 }\end{array}$ & $\begin{array}{c}\text { Percentagem de área } \\
\text { foliar infetada } \\
\text { (escala de 0-9)* }\end{array}$ & $\begin{array}{c}\text { Incidêucia de } \\
\text { cancro no caule } \\
(\mathbf{\%})^{* *}\end{array}$ & $\begin{array}{c}\text { Número total de } \\
\text { frutos (NTF)/15 } \\
\text { Plantas** }\end{array}$ & $\begin{array}{c}\text { Frutos infetados } \\
\text { (FI) /15 plantas** }\end{array}$ & $\begin{array}{c}\text { Produtividade } \\
\text { (ton/ha)* }\end{array}$ \\
\hline $30-20$ & 11,0 & 0,2 & $17,6 \mathrm{~b}^{* * *}$ & 3,1 & $45,5 \mathrm{~b}^{* * * *}$ \\
$90-60$ & 11,3 & 0,5 & $19,2 \mathrm{a}$ & 3,1 & $49,9 \mathrm{a}$ \\
\hline Coeficiente de variação & 34,2 & 25,7 & 6,3 & 21,8 & 5,2 \\
\hline
\end{tabular}

*Dados originais transformados em arcoseno $\sqrt{ } \mathrm{x}+1 / 100$;

**Dados originais transformados em $\sqrt{ } \mathrm{x}+1$;

***Médias seguidas da mesma letra nas colunas não diferem entre si, de acordo com o teste de Tukey, $5 \%$.

ativos também foi observado neste estudo até para fungicidas que não foram eficazes quando aplicados isoladamente, como foi o caso do tiofanato metílico e difenoconazole. Rizzo et al. (2003) verificaram bom controle do cancro das hastes em melão rendilhado (Cucumis melo L.) na aplicação do difenoconazole em mistura com acibenzolar-s-metílico.

De um modo geral, não houve efeito significativo dos deve estar consciente de que os ferimentos favorecem o surgimento da doença. No presente estudo os sintomas no caule surgiram aos 20 DAP nos dois ensaios, logo após a primeira capina, sugerindo que os ferimentos podem ter favorecido a doença. Observou-se que a incidência da doença no caule não aumentou muito, mas provavelmente foi importante como fonte inicial de inóculo para as infecções 
Controle químico do crestamento gomoso do caule na cultura...

TABELA 4 -Valores médios da percentagem de área foliar infetada da melancia (Citrullus lanatus) submetida a fungicidas em diferentes dias após o plantio (DAP), no Projeto Formoso, Ensaio I

\begin{tabular}{|c|c|c|c|c|c|c|}
\hline \multirow{2}{*}{ Tratamento (Fungicidas, i.a.) } & \multicolumn{4}{|c|}{ "Dias após o plantio-DAP* } & \multirow{2}{*}{ Equação da regressão** } & \multirow{2}{*}{$\mathbf{r}^{2}$} \\
\hline & 47 & 52 & 58 & 68 & & \\
\hline Tiof. metil. + clorotalonil & $0,0 \mathrm{~A}^{* *}$ & $0,06 \mathrm{~A}^{* * *}$ & $3,0 \mathrm{c} \mathrm{A} * * *$ & $3,0 \subset \mathrm{A}^{* * *}$ & $Y=0,1644 X-7,7344$ & 0,75 \\
\hline Mancozeb + difenoconazole & $0,0 \mathrm{~A}$ & $0,25 \mathrm{~A}$ & $3,0 \mathrm{cA}$ & $3,0 \mathrm{c} \mathrm{A}$ & $Y=0,1611 X-7,5013$ & 0,76 \\
\hline Mancozeb & $0,0 \mathrm{~A}$ & $1,18 \mathrm{~A}$ & $3,0 \mathrm{cA}$ & $3,0 \mathrm{c} \mathrm{A}$ & $Y=0,145 X-6,3604$ & 0,79 \\
\hline Trifloxistrobina + propiconazole & $0,0 \mathrm{~A}$ & $0,12 \mathrm{~A}$ & $2,3 \mathrm{c} \mathrm{A}$ & $3,0 \mathrm{c} \mathrm{A}$ & $Y=0,1584 X-7,5542$ & 0,88 \\
\hline Oxicloreto de cobre & $0,06 \mathrm{~A}$ & $0,37 \mathrm{~A}$ & $4,5 \mathrm{c} \mathrm{A}$ & $4,5 \mathrm{c} \mathrm{A}$ & $Y=0,2394 X-11,111$ & 0,76 \\
\hline Tebuconazole & $0,0 \mathrm{C}$ & $0,50 \mathrm{C}$ & 9,0 bc $\mathrm{B}$ & 47,2 b A & $Y=2,3217 X-116,42$ & 0,87 \\
\hline Tiofanato metílico & $1,0 \mathrm{C}$ & $2,93 \mathrm{C}$ & $13,5 \mathrm{~b} \mathrm{~B}$ & 65,7 a $\mathrm{A}$ & $Y=3,162 X-157,08$ & 0,88 \\
\hline Difenoconazole & $1,5 \mathrm{C}$ & $4,75 \mathrm{C}$ & 17,7 b B & $60,0 \mathrm{ab} \mathrm{A}$ & $Y=2,8679 X-140,33$ & 0,92 \\
\hline Carbendazim & $0,37 \mathrm{C}$ & $2,06 \mathrm{C}$ & $19,2 \mathrm{ab} B$ & 65,7 a $\mathrm{A}$ & $Y=3,2417 X-160,51$ & 0,92 \\
\hline Testemunha (sem fungicida) & $1,62 \mathrm{C}$ & $3,87 \mathrm{C}$ & 30,7 a B & 65,7 a $\mathrm{A}$ & $Y=3,2452 X-157,07$ & 0,96 \\
\hline
\end{tabular}

*Dados originais transformados em arcoseno $\sqrt{ } \mathrm{x}+1 / 100$;

** Equação da curva de progresso da doença em cada tratamento, onde $\mathrm{Y}=$ porcentagem de área foliar infetada e $\mathrm{X}=\mathrm{DAP}$;

***Médias seguidas de letra minúscula nas colunas e maiúscula nas linhas não diferem entre si, de acordo com o teste de Tukey, $5 \%$.

TABELA 5 - Valores médios da Área Abaixo da Curva de Progresso de Doença (AACPD), Incidência de cancro no caule, número total de frutos (NTF), Total de frutos infetados e produtividade da melancia (Citrullus lanatus) submetida ao tratamento com fungicidas, no Projeto Formoso, Ensaio II

\begin{tabular}{|c|c|c|c|c|c|}
\hline $\begin{array}{l}\text { Tratamento } \\
\text { (Fungicidas, P.C.) }\end{array}$ & $\begin{array}{c}\text { AACPD da \% } \\
\text { área foliar } \\
\text { infetada }\end{array}$ & $\begin{array}{c}\text { Incidência de } \\
\text { cancro no caule } \\
(\%)^{*}\end{array}$ & $\begin{array}{c}\text { Número total de } \\
\text { frutos NTF } / 15 \\
\text { Plantas } * *\end{array}$ & $\begin{array}{l}\text { Frutos infetados } \\
\text { (FI)/15 plantas** }\end{array}$ & $\begin{array}{l}\text { Produtividade } \\
\text { (Ton/ha)** }\end{array}$ \\
\hline Tiof. metil. + clorotalonil & $65,5 \mathrm{e}^{* * *}$ & 0,0 & 22,1 & 5,6 & $50,0 \mathrm{a}^{* * *}$ \\
\hline Mancozeb + difenoconazole & $68,7 \mathrm{de}$ & 0,0 & 22,3 & 4,2 & $48,2 \mathrm{a}$ \\
\hline Mancozeb & $68,7 \mathrm{de}$ & 0,0 & 21,8 & 6,0 & $45,8 \mathrm{ab}$ \\
\hline Trifloxistrobina + propiconazole & $97,5 \mathrm{~d}$ & 0,0 & 19,1 & 4,5 & $37,7 \mathrm{~cd}$ \\
\hline Oxicloreto de cobre & $159,7 \mathrm{c}$ & 0,4 & 20,6 & 6,2 & $45,0 \mathrm{abc}$ \\
\hline Tebuconazole & $344,7 \mathrm{a}$ & 0,0 & 20,1 & 3,7 & 39,8 bcd \\
\hline Tiofanato metílico & $298,2 \mathrm{~b}$ & 0,0 & 19,6 & 3,8 & $37,0 \mathrm{~cd}$ \\
\hline Difenoconazole & $298,1 \mathrm{~b}$ & 0,0 & 21,8 & 3,8 & $37,3 \mathrm{~cd}$ \\
\hline Carbendazin & $297,9 \mathrm{~b}$ & 0,4 & 20,1 & 5,8 & $37,7 \mathrm{~cd}$ \\
\hline Testemunha (sem fungicida) & $298,0 \mathrm{~b}$ & 1,2 & 20,3 & 4,8 & $33,1 \mathrm{~d}$ \\
\hline Coeficiente de Variação & 8,9 & 23,0 & 6,0 & 20,4 & 11,6 \\
\hline
\end{tabular}

subseqüentes nas folhas. Como o crestamento gomoso do caule, nas condições em que foi realizado este ensaio (umidade relativa menor que $75 \%$, na maior parte do período) não infetou os frutos, não se verificou de um modo geral efeito da doença no número total de frutos e no total de frutos infetados.

$\mathrm{O}$ crestamento nas folhas progrediu mais rapidamente a partir dos 52 DAP em todos os tratamentos (Figura $1 \mathrm{~A} \mathrm{e}$ B). Outros autores também verificaram maior evolução a partir dos 50 DAP (Keinath, 1995). Segundo Rotem \& Palti (1969), neste estágio de desenvolvimento da cultura uma densa camada de folhas e ramos retarda a evaporação da água e aumenta o período de molhamento foliar. O fungo D.bryoniae precisa de apenas $1 \mathrm{~h}$ de molhamento foliar para infetar as folhas de cucurbitáceas, sendo que, para a expansão da lesão é necessário o molhamento foliar por um período mais prolongado (Arny \& Rowe, 1991; Van Steekelenburg, 1985).

Maiores produtividades foram observadas nos tratamentos onde ocorreu maior controle da doença, indicando uma influência direta desta sobre a produtividade. Keinath (2001) verificou que os danos na produtividade ocorreram devido à redução no peso dos frutos, destruição das folhas e aumento de frutos queimados pelo sol. No ensaio I, onde verificou-se de um modo geral menores níveis de doença, os tratamentos tiofanato metílico + clorotalonil e mancozeb + difenoconazole produziram respectivamente 11,7 e 10,4 t a mais do que a testemunha. Da mesma forma, no ensaio II, onde houve maior nível de doença, estes mesmos tratamentos foram os melhores e produziram 16,9 e 15,1 t de frutos comerciais a mais quando comparados com a testemunha. Keinath (1995), verificou que o clorotalonil aplicado isoladamente foi mais efetivo do que o benomil no controle do crestamento gomoso do caule. Porém, melhor eficácia de controle ocorreu na mistura dos dois fungicidas. Neste estudo, o tiofanato metílico e o difenoconazole aplicados isoladamente 
TABELA 6 - Percentagem de área foliar infetada em plantas de melancia (Citrulus lanatus) submetidas a diferentes fungicidas e dois níveis de adubação de cobertura com nitrogênio $(\mathrm{N})$ e potássio (K), no Projeto Formoso, Ensaio II

\begin{tabular}{|c|c|c|}
\hline \multirow{2}{*}{$\begin{array}{l}\text { Tratamento } \\
\text { (Fungicidas, P.C.) }\end{array}$} & \multicolumn{2}{|c|}{$\begin{array}{c}\text { Adubação de cobertura } \\
\text { (Kg.N-K/ha) F.30-00-20* }\end{array}$} \\
\hline & $60-40$ & $120-80$ \\
\hline Tiof. metil. + clorotalonil & $4,6 \mathrm{~d} \mathrm{~B} * *$ & $8,4 \mathrm{~d} \mathrm{~A}^{* *}$ \\
\hline Mancozeb + difenoconazole & $4,6 \mathrm{dA}$ & 4,6 e $\mathrm{A}$ \\
\hline Mancozeb & $4,6 \mathrm{dA}$ & 4,6 e $\mathrm{A}$ \\
\hline Trifloxistrobina + propiconazole & $6,0 \mathrm{~d} A$ & 6,0 de $\mathrm{A}$ \\
\hline Oxicloreto de cobre & 13,3 c A & $13,3 \mathrm{c} \mathrm{A}$ \\
\hline Tebuconazole & $22,6 \mathrm{~b} \mathrm{~A}$ & $22,6 \mathrm{~b} \mathrm{~A}$ \\
\hline Tiofanato metílico & 28,7 a $\mathrm{A}$ & 28,7 a $\mathrm{A}$ \\
\hline Difenoconazole & 28,7 a $\mathrm{A}$ & 28,7 a $\mathrm{A}$ \\
\hline Carbendazin & 28,8 a $\mathrm{A}$ & 28,8 a $\mathrm{A}$ \\
\hline Testemunha (sem fungicida) & 29,1 a $\mathrm{A}$ & 29,1 a A \\
\hline Coeficiente de Variação & \multicolumn{2}{|r|}{8,7} \\
\hline
\end{tabular}

eficientes no controle do crestamento gomoso do caule. Essa mistura é de particular importância, principalmente para o uso do tiofanato metílico, pois existem vários casos de resistência neste patossistema aos fungicidas do grupo dos benzimidazóis (Malathrakis \& Vakalounakis, 1983; Kato et al., 1984; Van Steekelenburg, 1985). Sabe-se que a mistura com um fungicida de amplo espectro, como é o caso do clorotalonil, reduz a probabilidade de surgimento da resistência. Além disso, o tiofanato metílico aplicado isoladamente foi o tratamento menos eficaz no ensaio I e esteve entre os menos eficientes no ensaio II.

As aplicações de fungicidas neste ensaio foram realizadas no período de sete a dez dias. Keinath (2001) observou que aplicações mais efetivas de mancozeb e clorotalonil foram realizadas com frequência semanal quando comparadas com aquelas feitas no intervalo de 14 dias. Segundo Keinath et al. (1997), a freqüência de aplicação é um fator de grande importância no controle do crestamento da melancia.

O NTF foi significativamente influenciado pela

TABELA 7 - Valores médios da percentagem de área foliar infetada, incidência de cancro no caule, número total de frutos (NTF), frutos infetados e produtividade da melancia (Citrulus lanatus) submetida a dois níveis de adubação de cobertura com nitrogênio (N) e potássio (K), no Projeto Formoso, Ensaio II

\begin{tabular}{|c|c|c|c|c|c|}
\hline $\begin{array}{l}\text { Adubação de cobertura } \\
\text { (Kg.N-K/ha) F.30-00-20) }\end{array}$ & $\begin{array}{c}\% \text { área foliar } \\
\text { infetada } \\
\text { (escala de 0- 9)* }\end{array}$ & $\begin{array}{c}\text { Incidência de } \\
\text { cancro no caule } \\
(\%)^{*}\end{array}$ & $\begin{array}{l}\text { Total de frutos } \\
\text { (TF)/15 plantas** }\end{array}$ & $\begin{array}{l}\text { Frutos infetados } \\
\text { (FI)/15 plantas** }\end{array}$ & $\begin{array}{l}\text { Produtividade } \\
\text { (tOn/ha)*** }\end{array}$ \\
\hline $60-40$ & 17,1 & 0,1 & $20,0 b^{* * *}$ & 5,1 & $38,5 \mathrm{~b}^{* * *}$ \\
\hline $120-80$ & 17,5 & 0,2 & $21,5 \mathrm{a}$ & 4,5 & $43,8 \mathrm{a}$ \\
\hline Coeficiente de variação & 8,7 & 23,0 & 6,0 & 20,4 & 11,6 \\
\hline
\end{tabular}

*Dados originais transformados em arcoseno $\sqrt{ } \mathrm{x}+1 / 100$

**Dados originais transformados em $\sqrt{ } \mathrm{x}+1$;

***Médias seguidas da mesma letra nas colunas não diferem entre si, de acordo com o teste de Tukey, $5 \%$.

TABELA 8 - Valores médios da percentagem de área foliar infetada da melancia (Citrulus lanatus) submetida a fungicidas em diferentes dias após o plantio (DAP), no Projeto Formoso, Ensaio II

\begin{tabular}{|c|c|c|c|c|c|c|}
\hline \multirow{2}{*}{ Tratamento (Fungicidas, P.C.) } & \multicolumn{4}{|c|}{ Dias após o plantio-DAP* } & \multirow{2}{*}{ Equação da regressãa*** } & \multirow{2}{*}{$\mathbf{r}^{2}$} \\
\hline & 47 & 52 & 58 & 68 & & \\
\hline Tiof. metil. + clorotalonil & $0,0 \mathrm{C}^{* * *}$ & $0,81 \mathrm{bc} \mathrm{C}^{* * *}$ & $4,5 \mathrm{c} \mathrm{B} * * *$ & $20,7 \mathrm{c} \mathrm{A}^{* * *}$ & $Y=1,0119 X-50,4$ & 0,89 \\
\hline Mancozeb + difenoconazole & $0,0 \mathrm{C}$ & $0,50 \mathrm{c} \mathrm{C}$ & $3,0 \mathrm{c} \mathrm{B}$ & $15,0 \mathrm{dA}$ & $Y=0,7329 X-36,6$ & 0,88 \\
\hline Mancozeb & $0,0 \mathrm{C}$ & $0,50 \mathrm{c} \mathrm{C}$ & $3,0 \mathrm{c} \mathrm{B}$ & $15,0 \mathrm{dA}$ & $Y=0,7329 X-36,6$ & 0,88 \\
\hline Trifloxistrobina + propiconazole & $0,0 \mathrm{C}$ & $0,50 \mathrm{c} \mathrm{C}$ & $3,0 \mathrm{c} \mathrm{B}$ & $20,7 \mathrm{c} \mathrm{A}$ & $Y=1,0065 X-50,5$ & 0,85 \\
\hline Oxicloreto de cobre & $0,0 \mathrm{C}$ & $0,50 \mathrm{c} \mathrm{C}$ & $15,0 \mathrm{~b} \mathrm{~B}$ & $38,0 \mathrm{~b} \mathrm{~A}$ & $Y=1,9229 X-94,7$ & 0,94 \\
\hline Tebuconazole & $0,0 \mathrm{C}$ & $0,50 \mathrm{c} \mathrm{C}$ & $15,0 \mathrm{~b} \mathrm{~B}$ & 75,0 a $\mathrm{A}$ & $Y=3,6992 X-185,4$ & 0,88 \\
\hline Tiofanato metílico & $0,12 \mathrm{D}$ & $1,75 \mathrm{abc} C$ & 38,0 a B & 75,0 a A & $Y=3,8374 X-187,1$ & 0,95 \\
\hline Difenoconazole & $0,06 \mathrm{D}$ & 1,75 abc C & 38,0 a B & 75,0 a A & $Y=3,8397 X 187,2$ & 0,95 \\
\hline Carbendazin & $0,12 \mathrm{D}$ & $2,43 \mathrm{ab} C$ & 38,0 a B & 75,0 a $\mathrm{A}$ & $Y=3,8256 X-186,3$ & 0,95 \\
\hline Testemunha (sem fungicida) & $0,50 \mathrm{D}$ & 3,00 a C & 38,0 a B & $75 \mathrm{aA}$ & $Y=3,8013 X-184,7$ & 0,95 \\
\hline
\end{tabular}

*Dados originais transformados em arcoseno $\sqrt{ } \mathrm{x}+1 / 100$;

**Equação da curva de progresso da doença em cada tratamento, onde $\mathrm{Y}=$ porcentagem de área foliar infetada e X=DAP;

***Médias seguidas de letra minúscula nas colunas e maiúscula nas linhas não diferem entre si, de acordo com o teste de Tukey, 5\%.

não foram eficazes, mas as misturas do tiofanato metílico + clorotalonil e do difenoconazole + mancozeb, mostraram-se adubação de cobertura. Assim, nos dois ensaios, os maiores níveis de adubação com N-K proporcionaram maiores NTF 
Controle químico do crestamento gomoso do caule na cultura...
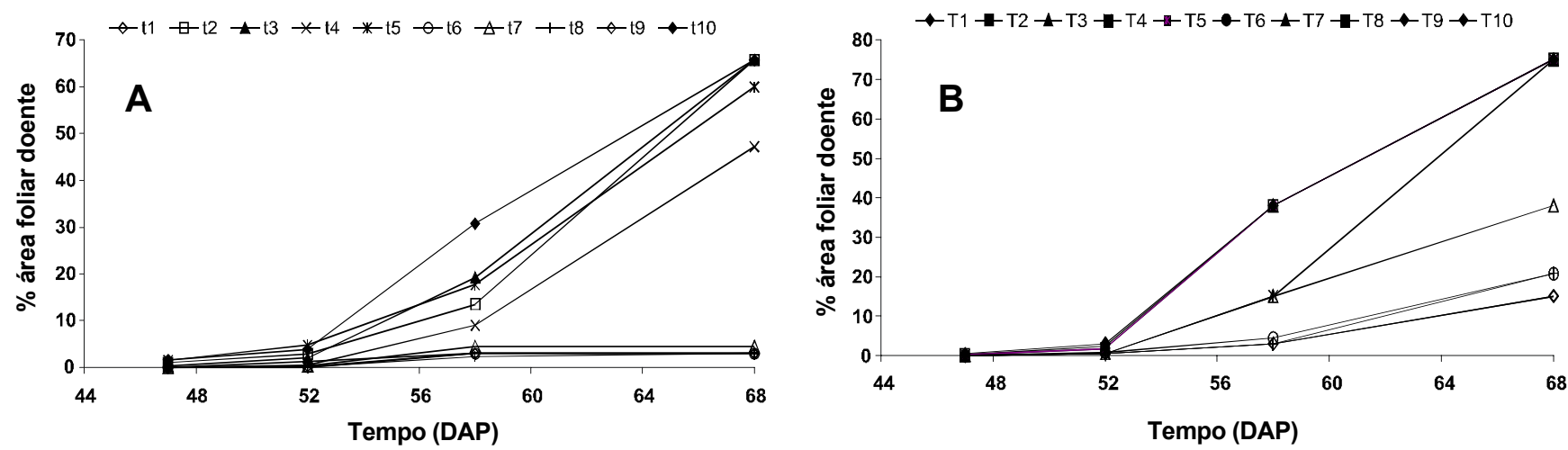

FIG. 1 - Curvas de progresso do crestamento gomoso do caule da melancia (Citrullus lanatus), cv. Crimson Sweet, em plantas tratadas com diferentes fungicidas, no Projeto Formoso, Ensaio I (A) e Ensaio II (B), sendo: T1-mancozeb-160,2 ml; T2-tiofanato metílico-49 g; T3carbendazim-500 ml; T4-tebuconazole-20 g; T5-difenoconazole-75 ml; T6-tiofanato metilico-40 g + clorotalonil-100 g; T7-oxicloreto de cobre-168 g; T8-trifloxistrobina-87,5 g + propiconazole-87,5 g; T9-mancozeb-80 ml + difenoconazole-37,2 ml e T10-testemunha (sem fungicida).
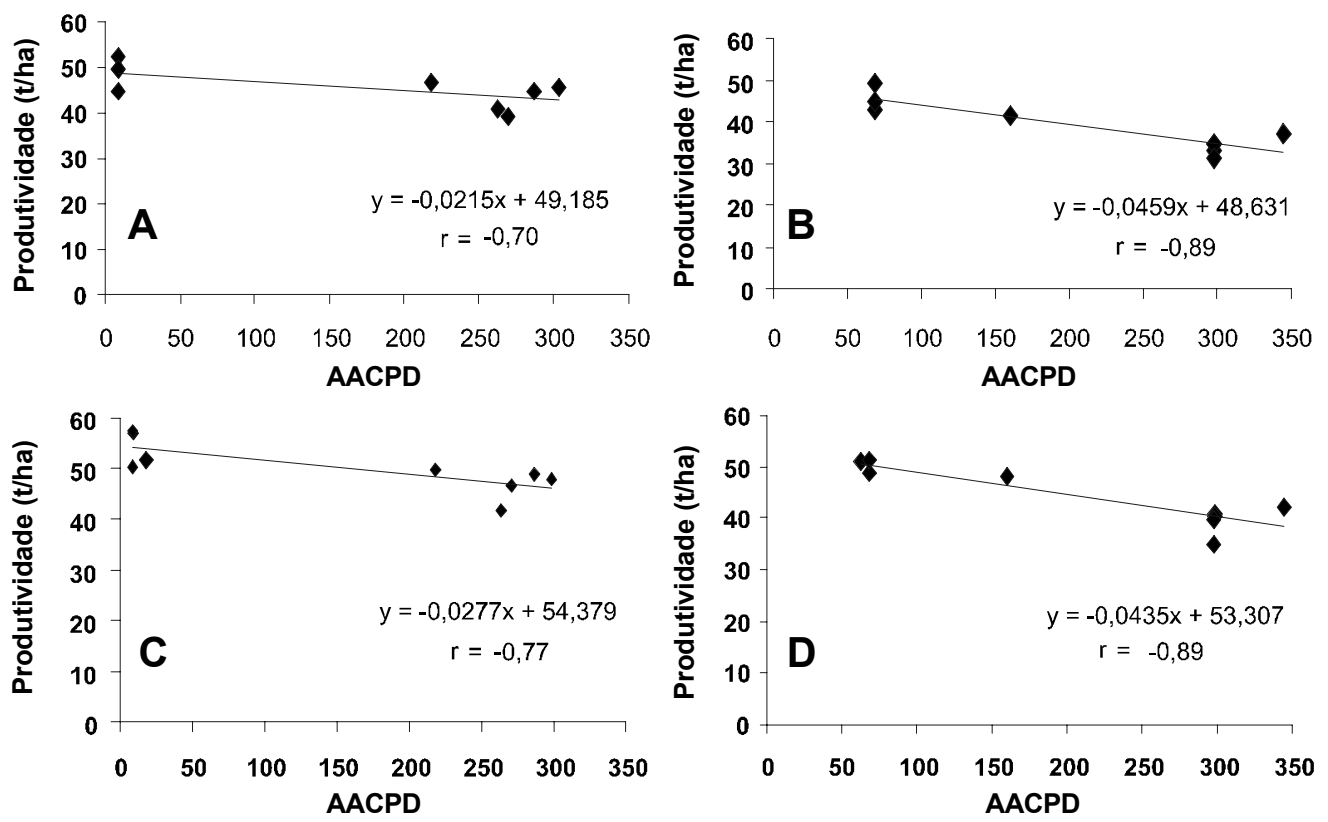

FIG. 2 - Efeito do crestamento gomoso do caule na produtividade da melancia (Citrullus lanatus), cv. Crimson Sweet, (AACPD), cujas plantas receberam respectivamente N-K em cobertura nas doses de 30-20 (A), 60-40 (B), 90-60 (C) e 120-80 (D) kg/ha, no Projeto Formoso.

(Tabelas 3 e 7). De acordo com Faquin (1994), além da função do potássio como ativador de grande número de enzimas relacionadas com os processos de assimilação de $\mathrm{CO}_{2}$ e de nitrogênio, ele tem ação na translocação e armazenamento de carboidratos. Costa et al. (2004), estudando a produção do melão rendilhado em função da concentração de potássio, verificaram que o incremento do potássio na solução nutritiva aumentou o número de frutos fixados e contribuiu para a redução do aborto de frutos. Porém, estes autores não constataram aumento na produção de frutos quando se elevou a concentração de potássio na solução nutritiva de 66 para 247,5

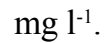

No presente trabalho, apesar do potássio associado ao nitrogênio ter proporcionado maior NTF nas maiores concentrações, o fator que teve maior influência direta na produtividade foi a área foliar infetada. Isto pode ser observado comparando-se os dois ensaios. No ensaio II, no qual foram aplicadas as maiores doses de $\mathrm{N}-\mathrm{K}$, foram encontrados maior índice de área foliar infetada, maior número de frutos e menor produtividade média, nas duas doses testadas. Maiores produtividades foram encontradas no ensaio I, onde se aplicaram menores doses e obtiveram-se menores números de frutos, porém as plantas tiveram menor índice de área foliar doente (Tabelas 3 e 7). Também se observou que o aumento na dose de N-K não afetou a área foliar infetada nos dois ensaios. 


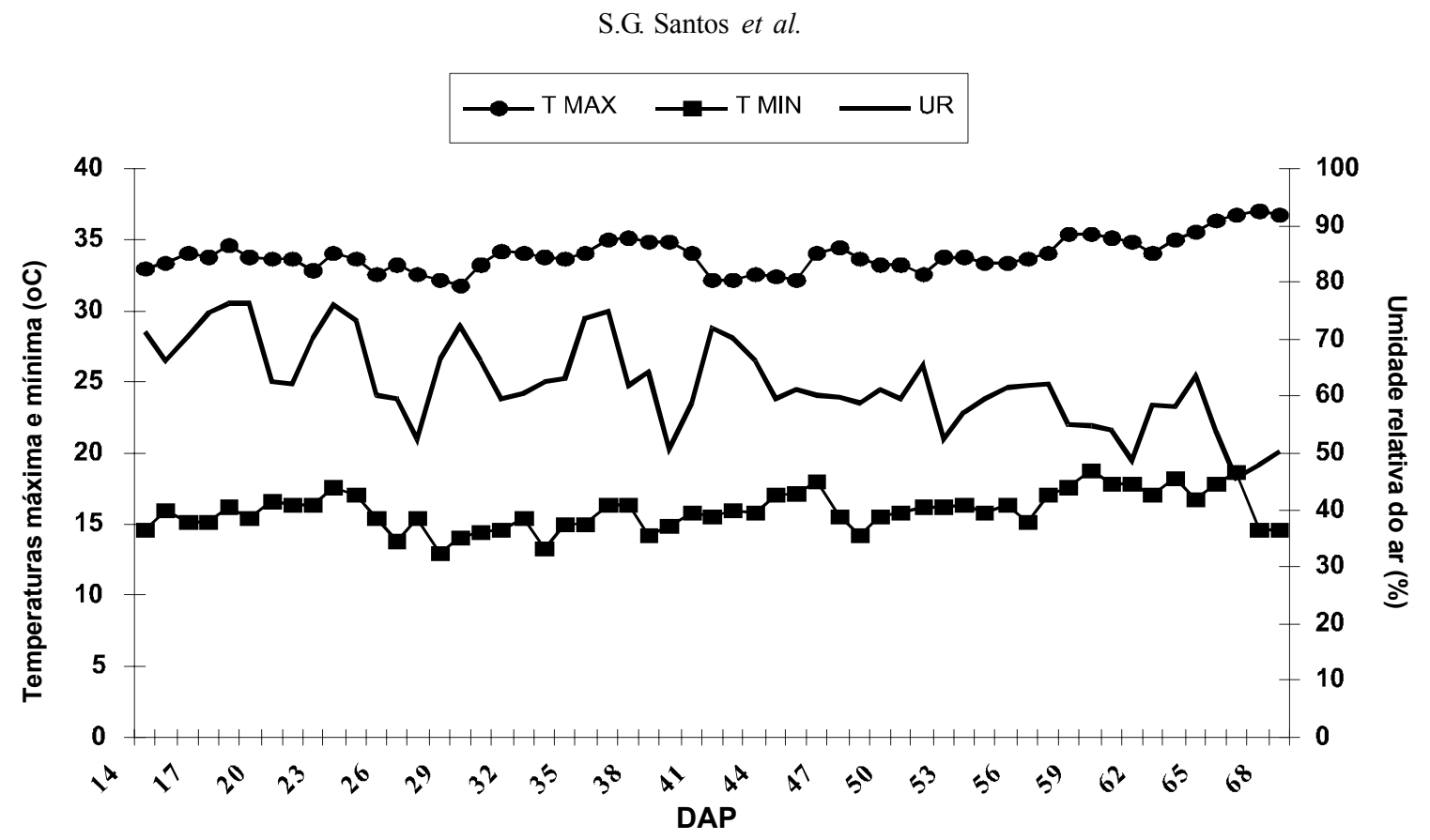

FIG 3 - Valores diários de temperaturas máxima e mínima $\left({ }^{\circ} \mathrm{C}\right)$ e umidade relativa do ar verificados no Projeto Formoso, Tocantins, 2003.

\section{AGRADECIMENTOS}

Trabalho recebeu apoio financeiro do Conselho Nacional de Desenvolvimento Científico e Tecnológico - CNPq - Processo no. 474194/2003-5.

\section{REFERÊNCIAS BIBLIOGRÁFICAS}

ALENCAR, I. Melancia. Revista Safra 22:43-45, 2001.

ANDREI, E. Compêndio de Defensivos Agrícolas. Guia Prático de Produtos Fitossanitários para Uso Agrícola, 6º ed. SP, 1999.

ANDREI, E. Compêndio de Defensivos Agrícolas. Guia Prático de Produtos Fitossanitários para Uso Agrícola-Complemento de atualização, v.II, $6^{\circ}$ ed. SP, 2003.

ARNY, C.J. \& ROWE, R.C. Effects of temperature and duration of surface wetness on spore production and infection of cucumbers by Didymella bryoniae. Phytopathology 81:206-209. 1991.

BALA, G. \& HOSEIN, F. Studies on gummy stem blight disease of cucurbits in Trinidad. Tropical Agriculture 63:195-197. 1986.

CÉSAR, N.S. \& SANTOS, G.R. Doenças da cultura da melancia no Projeto Formoso, Tocantins. Fitopatologia Brasileira 26:411. 2001 (Resumo).

COSTA,C.C., CECÍlIO FILHO, A.B., CAVARIANNI, R.L. \& BARBOSA, J.C. Produção do melão rendilhado em função da concentração de potássio na solução nutritiva e do número de frutos por planta. Horticultura Brasileira 22:23-27. 2004.

DIAS, R.C.S., QUEIROZ, M.A. \& MENEZES, M. Identificação de fontes de resistência em melancia a Didymella bryoniae. Horticultura Brasileira 14:15-17, 1996.

EVERTS, K.L. First report of benomyl resistance of Didymella bryoniae in Delaware and Maryland. Plant Disease 83:304. 1999
(Abstract).

FAO-FAOSTAT-Situação da produção e área de hortaliças no Brasil, 2002. Database Results (disponível URL: http://apps.fao.org)

FAQUIN, V. Nutrição mineral de plantas. Lavras: ESAL: FAEPE, 1994. 227p.

FIGUEIREDO, M.B. \& CARDOSO, R.M.G. Ocorrência de Mycosphaerella melonis (Pass.) Chiu \& J.C. Walker em cultura de melancia no estado de São Paulo. O Biológico 30:324-325. 1964.

FIGUEIREDO, M.B., CARDOSO, R.M.G. \& ABRAHÃO, J. Perdas causadas pelo fungo Mycosphaerella melonis (Pass.) Chiu \& J.C. Walker em aboboreira de moita. O Biológico 32:203-205. 1966.

GOMEZ, K.A. \& GOMEZ, A.A. Statistical Procedures for Agricultural Research. $2^{\text {nd }}$. Ed. John Wiley \& Sons, New York, 1983.

KATO, T., SUZUKI, K., TAKAHASHI, J. \& KAMOSHITA, K. Negatively correlated cross-resistance between benzimidazole fungicides and methyl N-(3-5-dichlorophenyl) carbamate. Journal of Pesticides Science 9:489-495. 1984.

KEINATH, A.P. \& DUTHIE, I.A. Yield and quality reductions in watermelon due to anthracnose, gummy stem blight and black rot. In: Recent Research Developments in Plant Pathology. v.2. Trivandrum, India. 1998. pp.77-90.

KEINATH, A.P. Effect of fungicide applications scheduled to control gummy stem blight on yield and quality of watermelon fruit. Plant Disease 85:53-58. 2001.

KEINATH, A.P. Fungicide timing for optimum management of gummy stem blight epidemics on watermelon. Plant Disease 79:354358. 1995.

KEINATH, A.P., MAY, W.H. \& DUBOSE, V.B. Comparison of eight fungicide intervals to control gummy stem blight on watermelon. Fungicides and Nematicides Tests 52:195. 1997 (Abstract).

MALATHRAKIS, N.E. \& VAKALOUNAKIS, D.J. Resistance to benzimidazole fungicides in the gummy stem blight pathogen 
Controle químico do crestamento gomoso do caule na cultura...

Didymella bryoniae on cucurbits. Plant Pathology 32:395-399. 1983.

MCGRATH, D.J., VAWDREY, L. \& WALKER, I.O. Resistance to gummy stem blight in muskmelon. HortScience 28:930-931. 1993.

RIZZO, A.A.N., FERREIRA, M.R. \& BRAZ, L.T. Ação de acibenzolar-s-methyl (BTH) isolado e em combinação com fungicidas no controle do cancro da haste em melão rendilhado. Horticultura Brasileira 21:238-240. 2003.

ROTEM, J. \& PALTI, J. Irrigation and plant diseases. Annual Review of Phytopathology 7:267-288. 1969.

SANTOS, G.R., CABRAL, M.M. \& DIDONET, J. Podridão de frutos de melancia causado por Sclerotium rolfsii no Projeto Formoso, Tocantins. Fitopatologia Brasileira 26:412. 2001 (Resumo).

SANTOS, G.R. \& CAFÉ-FILHO, A.C., REIS, A. \& LOPES, C.A. Progresso do crestamento gomoso do caule da melancia (Didymella bryoniae) em campo comercial. Fitopatologia Brasileira 28:226. 2003 (Resumo).

SCHENCK, N.C. Watermelon disease incidence in central Florida. Plant Disease Reporter 44:556-568. 1960.
SCHENCK, N.C. Epidemiology of gummy stem blight (Mycosphaerella citrulina) on watermelon:ascospore incidence and disease development. Phytopathology 58:1420-1422. 1968.

SHANER, G. \& FINNEY, R.E. The effect of nitrogen fertilization on the expression of slow - mildewing resistance in Knox Wheat. Phytopathology 67:1051-1056. 1977.

SITTERLY, W.R. \& KEINATH, A.P. Gummy stem blight. In:Zitter, T.A., Hopkins, D.L. \& Thomas, C.E. (Eds.) Compendium of Cucurbit Diseases. APS Press. St Paul. 1996. pp.27-28.

SUMNER, D..R. \& HALL, M.R. Resistance of watermelon cultivars to Fusarium wilt and gummy stem blight. Biological Culture Tests 8:36. 1993 (Abstract).

VAN STEEKELENBURG, N.A.M. Influence of humidity on incidence of Didymella bryoniae on cucumber leaves and growing points under controlled environmental conditions. Netherlands Journal of Plant Pathology 91:253-264. 1985.

WEHNER, T.C. \& St. AMAND, P.C. Field tests for cucumber resistance to gummy stem blight in North Carolina. HortScience 28:327-329. 1993. 